Published in final edited form as:

Sci Immunol. 2016 October 21; 1(4): . doi:10.1126/sciimmunol.aah6817.

\title{
Interferon-driven deletion of antiviral B cells at the onset of chronic infection
}

\author{
Benedict Fallet ${ }^{\# 1}$, Kerstin Narr ${ }^{\# 1}$, Yusuf I. Ertuna1 ${ }^{1}$, Melissa Remy ${ }^{1}$, Rami Sommerstein ${ }^{2}$, \\ Karen Cornille ${ }^{1}$, Mario Kreutzfeldt ${ }^{2,3}$, Nicolas Page ${ }^{2}$, Gert Zimmer $^{4}$, Florian Geier ${ }^{5}$, Tobias \\ Straub $^{6}$, Hanspeter Pircher ${ }^{6}$, Kevin Larimore ${ }^{7,8}$, Philip D. Greenberg ${ }^{7,8}$, Doron Merkler ${ }^{2,3}$, \\ and Daniel D. Pinschewer ${ }^{1, \#}$
}

${ }^{1}$ Department of Biomedicine, Division of Experimental Virology, University of Basel, 4003 Basel, Switzerland ${ }^{2}$ Department of Pathology and Immunology, Geneva Faculty of Medicine, 1211 Geneva 4, Switzerland ${ }^{3}$ Division of Clinical Pathology, University Hospital Geneva, 1 rue Michel Servet, 1211 Geneva 4, Switzerland ${ }^{4}$ Institute of Virology and Immunology IVI, 3147 Mittelhäusern, Switzerland ${ }^{5}$ Department of Biomedicine, Bioinformatics Core Facility, University Hospital Basel, 4031 Basel, Switzerland ${ }^{6}$ Institute for Immunology, Department for Medical Microbiology and Hygiene, University Medical Center Freiburg, 79104 Freiburg, Germany ${ }^{7}$ Fred Hutchinson Cancer Research Center, University of Washington, Seattle, WA 98109, USA ${ }^{8}$ Department of Immunology, University of Washington, Seattle, Washington, WA 98109, USA

\# These authors contributed equally to this work.

\section{Abstract}

Inadequate antibody responses and perturbed B cell compartments represent hallmarks of persistent microbial infections, but the mechanisms whereby persisting pathogens suppress humoral immunity remain poorly defined. Using adoptive transfer experiments in the context of a chronic lymphocytic choriomeningitis virus (LCMV) infection of mice, we have documented rapid depletion of virus-specific B cells that coincided with the early type I interferon response to infection. We found that the loss of activated B cells was driven by type I interferon (IFN-I) signaling to several cell types including dendritic cells, T cells and myeloid cells. Intriguingly, this process was independent of B cell-intrinsic IFN-I sensing and resulted from biased differentiation of naïve B cells into short-lived antibody-secreting cells. The ability to generate robust B cell responses was restored upon IFN-I receptor blockade or, partially, when experimentally depleting myeloid cells or the IFN-I-induced cytokines interleukin 10 and tumor necrosis factor alpha. We have termed this IFN-I-driven depletion of B cells "B cell decimation". Strategies to counter "B cell decimation" should thus help us better leverage humoral immunity in the combat against persistent microbial diseases.

\footnotetext{
\#Address correspondence to: D.P. (daniel.pinschewer@unibas.ch) Daniel D. Pinschewer, M.D., Department of Biomedicine - Haus Petersplatz, Petersplatz 10, 4009 Basel, Switzerland.

Author contributions: B.F., K.N., Y.E., M.R., R.S., K.C., G.Z., T.S., H.P., K.L., P.D.G., D.M., and D.D.P., contributed to experimental conception and design; B.F., K.N., Y.E., M.R., R.S., K.C., M.K., N.P., F.G., D.M., and D.D.P., acquired, analyzed and/or interpreted the data; B.F., K.N, and D.D.P., drafted or critically revised the article for important intellectual content.

Competing interests: The authors declare that they have no competing interests.
} 


\section{Introduction}

Humoral immunity represents a cornerstone of antimicrobial host defense and vaccine protection. Conversely, perturbed or dysfunctional B cell compartments constitute a hallmark of persistent microbial diseases including HIV, hepatitis B, hepatitis C, malaria, schistosomiasis and tuberculosis (1-5). Besides delayed and inadequate antibody responses to the causative agent itself $(6,7)$, consequences can consist in a generalized suppression of vaccine responses and B cell memory (8-10). In comparison to T cell exhaustion, however, the molecular mechanisms leading to viral subversion of the B cell system are less well understood.

Elevated expression levels of type I interferon (IFN-I) stimulated genes (ISGs) have been observed in chronic hepatitis $\mathrm{C}$ virus infection and chronic active tuberculosis, and have been shown in immunodeficiency virus infection to correlate with progression to AIDS (1114). Besides its essential role in antiviral host defense, IFN-I can apparently exert detrimental effects on antiviral $\mathrm{T}$ cell responses $(15,16)$. Conversely, a potential impact of IFN-I on B cell responses to chronic infection has remained ill-defined.

Chronic lymphocytic choriomeningitis virus (LCMV) infection of mice is widely used to study immune subversion in persistent infection. Delayed and weak neutralizing antibody $(\mathrm{nAb})$ responses alongside with $\mathrm{T}$ cell exhaustion represent characteristic features of this model as well as of human HIV and hepatitis C virus infection $(6,7)$. The LCMV envelope carries a glycan shield as a structural mechanism of nAb evasion $(17,18)$. Additionally, CD8 $\mathrm{T}$ cells, NK cells as well as inappropriate $\mathrm{T}$ cell help have been proposed to delay $\mathrm{nAb}$ formation to LCMV infection (19-22). In contrast, vesicular stomatitis virus (VSV) represents a prototypic acute infection, which triggers a rapid and potent nAb response (17).

Here we report that IFN-I-induced inflammation at the onset of chronic LCMV infection triggers unsustainable plasmablast responses, culminating in the depletion of virus-specific B cells. Mechanistic insights into this process should provide a conceptual basis to refine vaccination efforts and counter humoral immune subversion in persistent microbial diseases.

\section{Results}

\section{Depletion of virus-specific B cells at the onset of rCl13 but not rVSV infection}

Here we compared B cell responses to protracted LCMV infection (rCl13) and to recombinant vesicular stomatitis virus (rVSV) vaccine vectors. The two viruses were engineered to express the same surface glycoprotein (GP) as neutralizing antibody target, but served as prototypic models of chronic viremic and acute infection, respectively (Fig. 1A). To study antiviral B cell responses in mice, we adoptively transferred oligoclonal, traceable $\left(\mathrm{CD} 45.1^{+}\right) \mathrm{KL} 25 \mathrm{H}$ B cells, which contain $\sim 2 \%$ GP-specific cells owing to an immunoglobulin heavy chain knock-in (Fig. S1A). The transferred KL25H cells mounted only transient GP-specific antibody responses to rCl13, whereas rVSV infection induced sustained responses of higher titer (Fig. 1B). Moreover, KL25H B cell numbers at four weeks after rVSV immunization were $\sim 20$-fold higher than after rCl13 infection (Fig. 1C). We obtained analogous results, both in spleen and inguinal lymph nodes (iLN), when 
adoptively transferring quasi-monoclonal KL25HL B cells ( $85 \%$ GP-specific, Fig. S1A, B), which express the matching immunoglobulin light chain transgene in addition to the heavy chain knock-in (Fig. 1D, S1C). Four weeks after infection, KL25HL B cells populated the germinal centers (GCs) of rVSV-immunized mice but not of rCl13-infected animals (Fig. 1E). When studying (CD45.1 $1^{+}$donor) KL25HL B cells in the first week of rCl13 infection, they proliferated and were enlarged in shape, but they declined in numbers already on day 3 and disappeared almost completely by day 6 (Fig. 1F, G, S1D). On day three, the majority of proliferating (CFSE $\left.{ }^{\text {low }}\right)$ KL25HL B cells in rCl13-infected mice were apoptotic $\left(7 \mathrm{AAD}^{+} \mathrm{AnnexinV}^{+}\right.$, Fig. $\left.1 \mathrm{H}\right)$, whereas KL25HL B cells responding to rVSV remained mostly viable albeit proliferating at a comparable rate (Fig. 1G).

\section{B cell "decimation" correlates with the time point of cell transfer rather than with antigen load}

These observations suggested a near-complete apoptotic loss (referred to as "decimation") of virus-neutralizing KL25HL B cells within days after the onset of rCl13 infection. By analogy to T cells (23), high antigen loads in rCl13 but not rVSV infection could have accounted for antiviral B cell decimation. Counter to this hypothesis, adoptive transfer of KL25HL B cells into neonatally infected immunologically tolerant rCl13 carrier mice (24) resulted in robust B cell and plasmablast/plasma cell (antibody-secreting cell, ASC) formation despite high-level viremia (Fig. 2A and S2A, S2B; B cells and ASCs jointly referred to as "B cell progeny"). Furthermore, KL25HL B cell transfer on day 3 of rCl13 infection, when viremia had set in, yielded $\sim 20$-fold more B cell progeny than transfer at the onset of infection (Fig. 2B, C (22)). Day 3 transfer of KL25HL B cells resulted also in substantially higher neutralizing antibody $(\mathrm{nAb})$ responses and in a more potent antiviral effect than transfer on the day of infection (Fig. 2D, E). These observations argued against antigen overload as the root cause of KL25HL B cell decimation, suggesting rather that the inflammatory milieu at the onset of infection was unfavorable to sustained B cell responses.

\section{Type I interferon receptor blockade restores B cell expansion and GC B cell differentiation in rCl13 infection}

Intriguingly, this 3-day time window coincided with the strong systemic type I interferon (IFN-I) response in rCl13 infection (Fig. 3A). Moreover, rCl13-induced serum IFN-I responses clearly exceeded those induced by rVSV, and IFN-I was below technical backgrounds in $\mathrm{rCl} 13$ carriers, altogether suggesting an inverse correlation between systemic IFN-I levels and sustained antiviral B cell responses. Hence we speculated that rCl13induced IFN-I accounted for antiviral B cell decimation. Antibody-based blockade of the type I interferon receptor (aIFNAR) resulted in $\sim 20$-fold more KL25HL progeny on day 3 of rCl13 infection (Fig. 3B, C). By day 15, IFNAR blockade yielded $>100$-fold higher numbers of GL7 ${ }^{-}$(non-GC) KL25HL B cells and GL-7 $7^{+}(\mathrm{GC}) \mathrm{B}$ cells, both in spleen and iLN, and comparably elevated KL25HL progeny were found in bone marrow (BM, Fig. 3D and S3A). By immunohistochemistry we detected KL25HL B cells in GCs of IFNARblocked mice but not of control-treated animals (Fig. 3E). To investigate whether also antigen-experienced B cells were sensitive to IFN-I-driven decimation, we expanded KL25H $\mathrm{B}$ cells in vivo and transferred them to naive recipients, followed by $\mathrm{rCl} 13$ challenge (see Fig. S3B for set-up). The transferred cell population was largely antigen-specific ( $\sim 50 \%$ GP- 
binding) and comprised GL7 ${ }^{+}$(GC) as well as GL7 ${ }^{-}$cells but virtually no ASCs (Fig. S3C, D). IFNAR blockade yielded significantly more KL25H PCs and B cells on day 8 and day 67 after rCl13 challenge, respectively (Fig. 3F and S3E). Performing immunohistochemistry on day 67, we readily detected KL25H B cells in GCs of IFNAR-blocked but not controltreated recipients (Fig. 3G). While it cannot be determined at this point, whether the GL7 ${ }^{+}$ or $\mathrm{GL}^{-}$subset of antigen-experienced B cells or both were rescued by aIFNAR, neither subset formed substantial progeny upon rCl13 challenge unless IFNAR was blocked. We extended these adoptive transfer experiments to polyclonal LCMV-experienced B cells of GFP-transgenic $u b c-g f p$ mice (see Fig. S3F for set-up). On day 7 after rCl13 challenge, IFNAR-blocked recipients contained $\sim 30$-fold higher numbers of LCMV nucleoprotein (NP) -binding $\mathrm{GFP}^{+} \mathrm{B}$ cell progeny than control-treated animals (Fig. 3H and S3G). Altogether, this documented that not only primary responses of LCMV-specific KL25H and KL25HL B cells but also recall responses of antigen-experienced LCMV-specific B cells, both oligoclonal (KL25H) and polyclonal, were subject to IFN-I-driven decimation. Infection with rCl13 variants (25) exhibiting 6-fold and 30-fold lower affinity for KL25, respectively, yielded similarly low KL25HL progeny numbers as $\mathrm{rCl13}$, and all responses reached comparable levels when rescued by IFNAR blockade (Fig. S4A). This suggested that B cells of lower affinity could also be subject to IFN-I-driven decimation. Next we tested whether B cells of unrelated specificity, when activated concomitantly with rCl13 infection ("activated bystander B cells"), were similarly affected. We transferred traceable (CD45.2+) VI10 heavy chain knock-in B cells containing $~ 15 \%$ vesicular stomatitis virus glycoprotein (VSVG) specific B cells (26) into syngeneic $\left(\mathrm{CD} 45.1^{+}\right)$wt recipients. Subsequent immunization with VSVG triggered robust proliferation (CFSE dilution) and expansion of virtually all VSVGbinding VI10 B cells. This response was markedly reduced by concomitant $\mathrm{rCl13}$ infection but completely rescued by aIFNAR, extending the concept of IFN-I-driven decimation to activated bystander B cells (Fig. 3I). The use of (non-replicating) VSVG protein in these experiments corroborated that cognate antigen loads could not readily explain rCl13-driven B cell decimation. Moreover, rCl13 infection did not decimate VSVG-binding VI10 cells when concomitant VSVG immunization was omitted (Fig. S4B), suggesting that B cell receptor signaling was required for decimation.

\section{IFN-I-induced short-lived plasmablast differentiation in rCl13 infection}

aIFNAR prevented KL25HL B cell apoptosis as determined by flow cytometry (AnnexinV/ 7AAD binding) and by active caspase-3 staining in histology (Fig. 4A-C). To better understand IFN-I-driven B cell decimation, we performed whole genome RNA sequencing on KL25HL B cells recovered on day 3 of rCl13 infection. A pronounced antibody-secreting cell signature (27) was observed in control-treated cells, illustrated by the upregulation of prdm1 (encoding BLIMP1), sdc1 (encoding CD138), irf4 and $x b p 1$, and the downregulation of pax $5, b c 16, c x c r 5, c d 38$ and $c d 19$ expression, which were largely reversed by IFNAR blockade (Fig. 4D and S5A). This effect was also evident in aIFNAR-mediated suppression of ASC-related transcription factors (TF, Fig. S5B). Conversely, IFNAR blockade promoted/ restored TF expression profiles, which are typical for mature B cell stages prior to ASC differentiation (Fig. S5C). In line with its effects on the cells' ASC gene signature, aIFNAR altered the expression of 10 out of 13 genes, which have been linked to terminal B cell differentiation in human HIV infection (Fig. S5D, (28)). Flow cytometric analyses 
corroborated that IFNAR blockade impeded rCl13-induced ASC differentiation. As hallmarks of ASC differentiation, most KL25HL B cells in control-treated recipients lost B220, CD22 and CD23 expression as they proliferated (Fig. 4E). When IFNAR was blocked, a significantly higher proportion of KL25HL progeny cells retained these markers. Conversely, fewer KL25HL cells up-regulated the ASC marker CD138, and their intracellular IgM levels were lower (Fig. 4E). Altogether these observations indicated that IFNAR blockade prevented specific B cell decimation by countering short-lived plasmablast differentiation. In keeping with this interpretation, IFNAR blockade resulted in lower NPspecific IgM titers on day 4 after infection, but in higher IgG responses on day 8 (Fig. 4F).

\section{Decimation results from IFN-I effects on hematopoietic cells other than B cells, and is due to inflammation including IL-10 and TNF-a}

To differentiate between B cell-intrinsic and -extrinsic IFNAR effects on B cell decimation we used IFNAR-deficient and -sufficient KL25HL B cells for adoptive transfer. Both B cell types expanded vigorously when challenged with $\mathrm{rCl}_{13}$ in ifnar ${ }^{-/}$recipients but yielded low progeny numbers when responding in wt recipients (Fig. 5A). This suggested B cellextrinsic IFN-I effects as the root cause of rCl13-induced B cell decimation. We extended these observations to activated bystander B cells. IFNAR-deficient and -sufficient VI10 B cells responded similarly to VSVG protein immunization, and both responses were equally suppressed by concomitant rCl13 infection (Fig. 5B). When using reciprocal wt and ifnar ${ }^{r /-}$ BM chimeras as recipients we found that hematopoietic IFNAR expression was sufficient for KL25HL B cell decimation (Fig. 5C). The comparison of ifnar $/-\rightarrow$ ifnar-/- and ifnar ${ }^{-} \rightarrow \mathrm{wt}$ chimeras suggested an additional albeit modest impact of non-hematopoietic IFNAR on ASC numbers. To dissect how IFNAR signaling in various immune cell types contributed to B cell decimation we exploited cell type-specific IFNAR deletion models. KL25HL B cell progeny were significantly more numerous when recipients lacked IFNAR in either T cells (ifnar ${ }^{f l / f} c d 4$-cre), dendritic cells (ifnar ${ }^{f l / l f} c d 11$ c-cre) or myeloid cells (ifnar ${ }^{f l / f l} L y s M$-cre). IFNAR deletion in the recipient's B cells (ifnar ${ }^{f l f l}$ cd19-cre) only modestly augmented KL25HL ASCs, and neither of the above cell-type specific IFNAR deletion models fully phenocopied plain ifnar ${ }^{-/}$recipients (Fig. 5D). While the fidelity of these tissue-specific Cre deletion models has limitations, these data suggested that B cell decimation resulted from IFNAR signaling to several cell types such as myeloid cells, $\mathrm{T}$ cells and DCs. The essential antiviral role of IFN-I may preclude the success of aIFNARbased immunomodulatory therapy $((15,16,29)$, Fig. S6A). Also T cells and DCs are widely recognized as essential components of antiviral immune defense, but inhibition or depletion of myeloid cells can be pursued to combat persistent infection and cancer $(30,31)$. Hence we tested whether, by analogy to myeloid cell-specific IFNAR deficiency, myeloid cell depletion could rescue KL25HL B cell responses. Albeit less dramatically than aIFNAR, also a Gr-1 (Ly6C/G) antibody depletion, a widely used means to deplete myeloid cells in mice, augmented KL25HL progeny (Fig 5E). Of note, a Gr-1 depletion did not substantially affect viral loads or serum IFN-I kinetics (Fig. S6A, B), attesting to the potential utility of myeloid cell-targeting strategies for countering B cell decimation. In accordance with earlier reports, however, a Gr-1 depleted not only inflammatory monocytes (InfMo) and neutrophils but also eosinophils, plasmacytoid dendritic cells (pDCs) and $\mathrm{Ly}_{6 \mathrm{C}}$ high $\mathrm{CD} 8^{+} \mathrm{T}$ cells (Fig. S6C, D). Yet, the individual depletion of neutrophils, eosinophils or pDCs did not increase 
KL25HL B cell progeny, and $c d 8^{-/-}$mice yielded only modestly elevated numbers of KL25HL ASCs (Fig. S6E). aCD8 antibody depletion exerted a more pronounced effect (19) albeit not phenocopying IFNAR blockade either, and the depletion of CD8 $a^{+}$DCs (32) may have contributed to this B cell sparing effect (Fig. S6F). CD4 T cell depletion or NK cell depletion did not augment KL25HL progeny, and aIFNAR restored KL25HL B cell responses also in $\mathrm{CD}^{+}{ }^{+} \mathrm{T}$ cell-depleted mice (Fig. S6F, G), suggesting that IFN-I-driven B cell decimation was not directly related to IFN-I and NK cell effects on T follicular helper cell responses $(20,33)$. To address a potential role of InfMo in B cell decimation we used both InfMo-deficient $c c r 2^{--}$and $k l f 4^{f l / f l} X$ Vav1-icre recipients (Fig. S6H-K and (34)). Neither model phenocopied the aGr-1 effect, and aGr-1 depletion improved KL25HL progeny recovery also in InfMo-deficient $c c r 2^{-/}$recipients (Fig S6K). Hence, the B cell-sparing effect of aGr-1 depletion likely represented its combined impact on multiple myeloid and perhaps even non-myeloid cell subsets. Thus we speculated that both aGr-1 and aIFNAR countered antiviral B cell decimation by altering virus-induced inflammation. When profiling the expression of 248 inflammation-related genes in spleen, 128 were altered upon rCl13 infection, and aIFNAR attenuated or prevented a majority of these inflammatory gene expression changes (Fig. 5F, S7A B, Tbl. SI). a Gr-1 also exerted clear albeit less wideranging effects, and a majority of a Gr-1-mediated gene expression changes such as in oasl1, ifit2, ifit 3 and $i 110$ were also covered by aIFNAR (17/25=69\% in spleen; $13 / 17=76 \%$ in BM, Fig. S7C, D, Tbl, SI). In a serum cytokine panel analysis, 19 out of 31 tested chemokines and cytokines increased at 24 and 72 hours after rCl13 infection, respectively, and were at least 4-fold suppressed by aIFNAR (Fig. 5G, Table. SII). Eight of these 19 were also significantly suppressed, albeit less potently, in aGr-1-treated animals (red bars in Fig. 5G). Taken together, IFNAR deficiency and, to a lesser extent also a Gr-1, modulated rCl13induced systemic inflammation, and most a Gr-1 effects on inflammation were comprised in the aIFNAR effects. These observations raised the possibility that the IFN-I-induced inflammatory milieu in rCl13 infection caused B cell decimation by altering B cell survival and/or differentiation signals. This hypothesis predicted that i) the supplementation of survival signals and also ii) the depletion of deleterious inflammatory mediators or blockade of death pathways should augment specific B cell responses in rCl13 infection. In line with prediction i), KL25HL B cell transfer and rCl13 infection yielded $\sim 10$-fold more progeny when performed in transgenic recipients artificially overexpressing the B cell survival factor BAFF (Fig. S8A). In attempting to test prediction ii) we used knock-out mouse models and antibody depletion approaches to assess the individual contribution of IL-1 $\beta$, IL-4, IL-6, IL-10, IL-12, TNF- $\mathrm{a}$, iNOS and FasL to rCl13-induced KL25HL B cell decimation. KL25HL B cells yielded significantly more progeny when challenged with rCl13 in IL-10deficient or TNF-a-blocked recipient mice (Fig 5H, I). While we failed to detect a statistically significant individual role for IL-1 $\beta$, IL-4, IL-6, IL-12, iNOS or FasL in B cell decimation (Fig. S8B-E), contributive effects of some of these and other IFN-I-induced factors and pathways $(28,35,36)$ remain likely. Accordingly, only their combined suppression alongside with IL-10 and TNF- $a$ may account for the potent B cell-sparing effect of IFNAR blockade. 


\section{Discussion}

IFN-I driven B cell decimation may reflect the immune system's attempt at maximizing early antibody production in a highly inflammatory context. In acute life-threatening infections, this ASC differentiation bias may augment survival chances by maximizing early immunoglobulin production and seems desirable from an evolutionary standpoint. Conversely, B cell decimation puts at risk the sustainability of humoral responses, both of naïve and immunized hosts, when confronted with persistence-prone pathogens.

Repertoire replenishment by new bone marrow emigrants $(22,37)$ and GC-driven evolution of low-affinity clones are predicted to eventually compensate for early repertoire decimation. These processes are thus likely to have supplied the B cells, which eventually formed GCs in rCl13-infected mice even when IFNAR signaling was intact (Figs. 1E, 3E, G). The sustained IFN-I transcriptome signatures in active tuberculosis, chronic hepatitis $\mathrm{C}$ virus and pathogenic immunodeficiency virus infection raise the possibility that $\mathrm{B}$ cell decimation extends into the chronic phase of infection (11-14) and may have long-term effects on B cell responses and memory $(6,8-10)$. While IFN-I warrants the host's survival in the acute phase of infection (29), persisting IFN-I-driven inflammation may thus paradoxically promote microbial evasion of humoral immunity in the chronic disease context.

Unlike IFN-I transcriptome signatures, which represent a common characteristic of many persistent microbial infections, individual IFN-I induced inflammatory mediators and their impact on immune responses can vary between infection settings. IFN-I-induced IL-10 and myeloid cells, for example, are known to regulate cellular immunity to LCMV in a virus strain- and load-dependent manner $(15,31,38)$. It thus seems noteworthy that IL-10 as well as TNF- $a$, which we identify as mediators of IFN-I-driven B cell decimation, have previously been linked to B cell dysfunction in HIV-1 infection $(35,39)$. DCs represent a main sources of IL-10 in chronic LCMV infection (15), offering a potential mechanism for these cells' contribution to IFN-I-driven B cell decimation.

While our work would have been technically challenging without the development of BCRengineered mice, we acknowledge that the use of this tool is a limitation of our study. The B cell receptor in question exhibits high affinity for GP and only a narrow range of loweraffinity GP variants could be tested, and limitation of the available flow cytometric methodology rendered detection of endogenous GP-specific B cells unreliable. Further, the majority of the work was focused on B cell responses to the GP as sole antigen, and the characterization of "decimated" B cell populations required the adoptive transfer of large numbers of receptor-engineered naïve B cells, well above their normal frequencies in the $\mathrm{B}$ cell repertoire of a naïve mouse. Finally, while we have provided several independent lines of evidence supporting the essential role of IFN-I in B cell decimation, it remains to be investigated whether IFN-I is sufficient to trigger this process.

In conclusion, IFN-I-driven B cell decimation offers a molecular mechanism for humoral immune subversion under conditions of persistent microbial inflammation. Our studies highlight the contributions of several immune cells and cytokines to B cell decimation, and these insights should be helpful in refining vaccination efforts against persisting pathogens. 


\section{Materials and Methods}

\section{Viruses, virus titrations, infections and immunizations}

LCMV strain Clone 13 expressing the LCMV strain WE glycoprotein (rCl13) and variants thereof containing either the N121K or N119D mutations (25) in GP, respectively, were engineered as described (40). A recombinant vesicular stomatitis virus vector expressing the LCMV strain WE glycoprotein instead of VSVG (rVSV) was generated following established procedures and strategies (41). rCl13 and rVSV were grown on BHK-21 cells and were titrated as described (17). Unless specified otherwise, rCl13 and rVSV were administered to mice intravenously (i.v.) at doses of $2 \times 10^{6}$ and $8 \times 10^{6}$ plaque-forming units (PFU), respectively. Adult infections were performed $30 \mathrm{~min}$. after adoptive B cell transfer. Neonatal infections were performed with $6 \times 10^{5} \mathrm{PFU}$ rCl13 into the skull within 24 hours after birth. VSV glycoprotein (VSVG) for immunization was produced in SF9 cells using a recombinant baculovirus system (17). $20 \mu \mathrm{g}$ whole cell lysate was administered to mice i.v..

\section{Flow cytometry and FACS sorting}

To prepare single cell suspensions, tibiae were flushed and spleens were enzymatically digested using collagenase D (Roche) and DNAseI (Sigma-Aldrich). Cell media were adjusted to mouse osmolarity. Staining reagents and procedures are reported in Supplementary Materials. Labelled cells were measured on Gallios (Beckman Coulter) and LSRFortessa (Becton Dickinson) flow cytometers. Data were analyzed using FlowJo software (Tree Star). FACS sorting of KL25HL B cells progeny was performed directly into TRI Reagent LS (Sigma-Aldrich) using an FACSAria II (Becton Dickinson, BD) cell sorter. RNA was extracted using the Direct-zol ${ }^{\mathrm{TM}}$ RNA MicroPrep kit (Zymo research).

\section{Immunohistochemistry and image analysis}

Tissues were fixed in HEPES-glutamic acid buffer-mediated organic solvent protection effect (HOPE, DCS Innovative) fixative as previously described (42) and embedded in paraffin. Immunostaining was performed on $3 \mu \mathrm{m}$ thick sections using antibodies against active caspase-3 (9661T, Cell Signaling) and CD45.1 (clone A20, FITC-labeled, BioLegend). Bound caspase-3 antibodies were visualized using tyramide signal amplification (Thermo-Fisher). Bound CD45.1 antibodies were visualized using rabbit antiFITC antibody followed by incubation with Alexa-fluor goat-anti-rabbit antibody (LifeTechnologies). Germinal centers were visualized using FITC-labeled Peanut agglutinin (PNA; Life technologies). Nuclei were stained with 4',6-diamidino-2-phenylindole (DAPI, Invitrogen). Image processing and analysis are described in Supplementary Methods.

\section{Whole-genome RNA sequencing and low-density inflammatory gene expression profiling}

For RNA sequencing of sorted KL25HL B cells, RNA was extracted using the Direct-zol ${ }^{\mathrm{TM}}$ RNA MicroPrep kit (Zymo research). Libraries were prepared using the TruSeq kit (Illumina) and sequencing was performed by 50 bp single-end reads on an Illumina HiSeq 2000 .

For low-density inflammatory gene expression profiling, spleen and BM RNA was extracted using Direct-zol ${ }^{\mathrm{TM}}$ RNA MicroPrep kit (Zymo research). Expression profiling was done 
using the nCounter Nanostring Mouse Inflammation v2 assay (NanoString Technologies). Statistical analysis of gene expression profiles is described in Supplementary Methods.

\section{Mice and animal experiments}

To generate KL25L transgenic mice, the expression cassette described in Fig. S1B was released from its vector and was injected into C57BL/6 embryos using standard techniques. Sources and references of previously published mouse lines as well as intercrosses are detailed in Supplementary Materials and Methods. All mice were kept under specificpathogen-free (SPF) conditions for colony maintenance and experiments. Experiments were performed at the Universities of Geneva and Basel, in accordance with the Swiss law for animal protection and with authorization by the respective Cantonal authorities.

\section{Adoptive cell transfer and fluorescent cell labeling}

For adoptive transfer of naïve B cells and subsequent analysis by flow cytometry, splenocyte suspensions $\left(2-4 \times 10^{6}\right.$ per recipient) in balanced salt solution were administered i.v. For histological assessments, MACS-purified B cells (Miltenyi Biotec Pan B cell isolation kit, for untouched B cells) were also used. Syngeneic C57BL/6J mice served as recipients, except for long-term ( $>1$ week) transfer of KL25HL cells, which were performed in KL25L recipients to avoid anti-idiotypic responses. To assess in vivo proliferation, splenocyte populations were labeled with Carboxyfluorescein succinimidyl ester (CFSE, SigmaAldrich) or CellTraceViolet (CTV, Life Technologies). The generation of antigenexperienced B cells for adoptive transfer is detailed in Supplementary Materials and Methods.

\section{Antibody, interferon- $a$ and cytokine/chemokine panel measurements}

GP-1-binding antibodies were measured as described (43). To discriminate responses of adoptively transferred KL25H B cells from endogenous responses in ELISA, background GP-1 antibody titers in control mice without KL25H cell transfer were determined and were subtracted.

rCl13-neutralizing antibodies (nAbs) were measured by immunofocus reduction assays (17). IFN- $a$ concentrations in serum were determined using the VeriKine Mouse Interferon Alpha ELISA Kit (PBL Assay Science). To profile inflammatory responses in mouse serum we used a laser bead-based 31-plex cytokine and chemokine array (Eve Biotechnologies).

\section{Statistical analysis}

For comparison of one parameter between two groups, unpaired two-tailed Student's $t$ tests were performed. One-way analysis of variance (ANOVA) was used to compare one parameter between multiple groups, two-way ANOVA for comparison of multiple parameters between two or more groups. ANOVA was followed by Bonferroni's post-test for multiple comparisons. Dunnett's post-test was used to compare multiple groups to a control group. With the exception of percentages, values were log-converted to obtain a near-normal distribution for statistical analysis. Data were analyzed using Graphpad Prism software (version 6.0h). $P$ values $>0.05$ were considered not significant (ns), $p$ values $<0.05$ were considered significant $(*, \#)$ and $p$ values $<0.01$ highly significant (**,\#\#). 


\title{
Data and materials availability
}

RNAseq and low-density gene expression profiling data are deposited with the National

Center for Biotechnology Information Gene Expression Omnibus (GEO, accession numbers GSE84037 and GSE84036 respectively).

\section{Supplementary Material}

Refer to Web version on PubMed Central for supplementary material.

\section{Acknowledgments}

\begin{abstract}
We wish to thank S. Sammicheli, M. Kuka and M. Iannacone for long-standing and open exchange about their closely related work; C.A. Siegrist, P.H. Lambert, J.C. Weill, J. Luban, T. Rolink, R. Tussiwand and M. Recher for helpful discussions and comments on the manuscript; D. Labes, G. Salinas, T. Lingner, S. Iuthin, F. Ludewig, D. Chollet and S. Clement for cell sorting, gene expression profiling, biomathematical analyses and immunohistochemistry.
\end{abstract}

Funding: This work was supported by the European Research Council (ERC grant No. 310962 to D.D.P.) and by the Swiss National Science Foundation (stipendiary professorships No. PP00P3_135442/1 to D.D.P and No. PP00P3_152928 to D.M.).

\section{References and Notes}

1. Moir S, Fauci AS. B-cell exhaustion in HIV infection: the role of immune activation. Curr Opin HIV AIDS. 2014; 9:472-477. [PubMed: 25023621]

2. Oliviero B, Cerino A, Varchetta S, Paudice E, Pai S, Ludovisi S, Zaramella M, Michelone G, Pugnale P, Negro F, Barnaba V, et al. Enhanced B-cell differentiation and reduced proliferative capacity in chronic hepatitis C and chronic hepatitis B virus infections. J Hepatol. 2011; 55:53-60. [PubMed: 21145853]

3. Weiss GE, Crompton PD, Li S, Walsh LA, Moir S, Traore B, Kayentao K, Ongoiba A, Doumbo OK, Pierce SK. Atypical memory B cells are greatly expanded in individuals living in a malaria-endemic area. J Immunol. 2009; 183:2176-2182. [PubMed: 19592645]

4. Labuda LA, Ateba-Ngoa U, Feugap EN, Heeringa JJ, van der Vlugt LE, Pires RB, Mewono L, Kremsner PG, van Zelm MC, Adegnika AA, Yazdanbakhsh M, et al. Alterations in peripheral blood B cell subsets and dynamics of B cell responses during human schistosomiasis. PLoS Negl Trop Dis. 2013; 7:e2094. [PubMed: 23505586]

5. Joosten SA, van Meijgaarden KE, Del Nonno F, Baiocchini A, Petrone L, Vanini V, Smits HH, Palmieri F, Goletti D, Ottenhoff TH. Patients with Tuberculosis Have a Dysfunctional Circulating B-Cell Compartment, Which Normalizes following Successful Treatment. PLoS Pathog. 2016; 12:e1005687. [PubMed: 27304615]

6. Chen M, Sallberg M, Sonnerborg A, Weiland O, Mattsson L, Jin L, Birkett A, Peterson D, Milich DR. Limited humoral immunity in hepatitis C virus infection. Gastroenterology. 1999; 116:135143. [PubMed: 9869611]

7. Cohen MS, Shaw GM, McMichael AJ, Haynes BF. Acute HIV-1 Infection. N Engl J Med. 2011; 364:1943-1954. [PubMed: 21591946]

8. Wheatley AK, Kristensen AB, Lay WN, Kent SJ. HIV-dependent depletion of influenza-specific memory B cells impacts B cell responsiveness to seasonal influenza immunisation. Sci Rep. 2016; 6:26478. [PubMed: 27220898]

9. Malaspina A, Moir S, Orsega SM, Vasquez J, Miller NJ, Donoghue ET, Kottilil S, Gezmu M, Follmann D, Vodeiko GM, Levandowski RA, et al. Compromised B cell responses to influenza vaccination in HIV-infected individuals. J Infect Dis. 2005; 191:1442-1450. [PubMed: 15809902]

10. Cunnington AJ, Riley EM. Suppression of vaccine responses by malaria: insignificant or overlooked? Expert Rev Vaccines. 2010; 9:409-429. [PubMed: 20370551] 
11. Bolen CR, Robek MD, Brodsky L, Schulz V, Lim JK, Taylor MW, Kleinstein SH. The blood transcriptional signature of chronic hepatitis $\mathrm{C}$ virus is consistent with an ongoing interferonmediated antiviral response. J Interferon Cytokine Res. 2013; 33:15-23. [PubMed: 23067362]

12. Berry MP, Graham CM, McNab FW, Xu Z, Bloch SA, Oni T, Wilkinson KA, Banchereau R, Skinner J, Wilkinson RJ, Quinn C, et al. An interferon-inducible neutrophil-driven blood transcriptional signature in human tuberculosis. Nature. 2010; 466:973-977. [PubMed: 20725040]

13. Mandl JN, Barry AP, Vanderford TH, Kozyr N, Chavan R, Klucking S, Barrat FJ, Coffman RL, Staprans SI, Feinberg MB. Divergent TLR7 and TLR9 signaling and type I interferon production distinguish pathogenic and nonpathogenic AIDS virus infections. Nat Med. 2008; 14:1077-1087. [PubMed: 18806803]

14. Rotger M, Dalmau J, Rauch A, McLaren P, Bosinger SE, Martinez R, Sandler NG, Roque A, Liebner J, Battegay M, Bernasconi E, et al. Telenti, Comparative transcriptomics of extreme phenotypes of human HIV-1 infection and SIV infection in sooty mangabey and rhesus macaque. J Clin Invest. 2011; 121:2391-2400. [PubMed: 21555857]

15. Wilson EB, Yamada DH, Elsaesser H, Herskovitz J, Deng J, Cheng G, Aronow BJ, Karp CL, Brooks DG. Blockade of chronic type I interferon signaling to control persistent LCMV infection. Science. 2013; 340:202-207. [PubMed: 23580528]

16. Teijaro JR, Ng C, Lee AM, Sullivan BM, Sheehan KC, Welch M, Schreiber RD, de la Torre JC, Oldstone MB. Persistent LCMV infection is controlled by blockade of type I interferon signaling. Science. 2013; 340:207-211. [PubMed: 23580529]

17. Pinschewer DD, Perez M, Jeetendra E, Bächi T, Horvath E, Hengartner H, Whitt MA, de la Torre JC, Zinkernagel RM. Kinetics of protective antibodies are determined by the viral surface antigen. J Clin Invest. 2004; 114:988-993. [PubMed: 15467838]

18. Sommerstein R, Flatz L, Remy MM, Malinge P, Magistrelli G, Fischer N, Sahin M, Bergthaler A, Igonet S, Ter Meulen J, Rigo D, et al. Arenavirus Glycan Shield Promotes Neutralizing Antibody Evasion and Protracted Infection. PLoS Pathog. 2015; 11:e1005276. [PubMed: 26587982]

19. Battegay M, Moskophidis D, Waldner H, Brundler MA, Fung-Leung WP, Mak TW, Hengartner H, Zinkernagel RM. Impairment and delay of neutralizing antiviral antibody responses by virusspecific cytotoxic T cells. J Immunol. 1993; 151:5408-5415. [PubMed: 7693811]

20. Cook KD, Kline HC, Whitmire JK. NK cells inhibit humoral immunity by reducing the abundance of CD4+ T follicular helper cells during a chronic virus infection. J Leukoc Biol. 2015; 98:153162. [PubMed: 25986014]

21. Recher M, Lang KS, Hunziker L, Freigang S, Eschli B, Harris NL, Navarini A, Senn BM, Fink K, Lotscher M, Hangartner L, et al. Zinkernagel, Deliberate removal of T cell help improves virusneutralizing antibody production. Nat Immunol. 2004; 5:934-942. [PubMed: 15300247]

22. Zellweger RM, Hangartner L, Weber J, Zinkernagel RM, Hengartner H. Parameters governing exhaustion of rare T cell-independent neutralizing IgM-producing B cells after LCMV infection. Eur J Immunol. 2006; 6:3175-3185.

23. Mueller SN, Ahmed R. High antigen levels are the cause of T cell exhaustion during chronic viral infection. Proc Natl Acad Sci U S A. 2009; 106:8623-8628. [PubMed: 19433785]

24. Pircher H, Burki K, Lang R, Hengartner H, Zinkernagel RM. Tolerance induction in double specific T-cell receptor transgenic mice varies with antigen. Nature. 1989; 342:559-561. [PubMed: 2573841]

25. Hangartner L, Zellweger RM, Giobbi M, Weber J, Eschli B, McCoy KD, Harris N, Recher M, Zinkernagel RM, Hengartner H. Nonneutralizing antibodies binding to the surface glycoprotein of lymphocytic choriomeningitis virus reduce early virus spread. J Exp Med. 2006; 203:2033-2042. [PubMed: 16880253]

26. Hangartner L, Senn BM, Ledermann B, Kalinke U, Seiler P, Bucher E, Zellweger RM, Fink K, Odermatt B, Burki K, Zinkernagel RM, et al. Antiviral immune responses in gene-targeted mice expressing the immunoglobulin heavy chain of virus-neutralizing antibodies. Proc Natl Acad Sci U S A. 2003; 100:12883-12888. [PubMed: 14569006]

27. Shi W, Liao Y, Willis SN, Taubenheim N, Inouye M, Tarlinton DM, Smyth GK, Hodgkin PD, Nutt SL, Corcoran LM. Transcriptional profiling of mouse B cell terminal differentiation defines a 
signature for antibody-secreting plasma cells. Nat Immunol. 2015; 16:663-673. [PubMed: 25894659]

28. Moir S, Malaspina A, Pickeral OK, Donoghue ET, Vasquez J, Miller NJ, Krishnan SR, Planta MA, Turney JF, Justement JS, Kottilil S, et al. Fauci, Decreased survival of B cells of HIV-viremic patients mediated by altered expression of receptors of the TNF superfamily. J Exp Med. 2004; 200:587-599.

29. Sandler NG, Bosinger SE, Estes JD, Zhu RT, Tharp GK, Boritz E, Levin D, Wijeyesinghe S, Makamdop KN, del Prete GQ, Hill BJ, et al. Type I interferon responses in rhesus macaques prevent SIV infection and slow disease progression. Nature. 2014; 511:601-605. [PubMed: 25043006]

30. Wesolowski R, Markowitz J, Carson WE 3rd. Myeloid derived suppressor cells - a new therapeutic target in the treatment of cancer. J Immunother Cancer. 2013; 1:10. [PubMed: 24829747]

31. Norris BA, Uebelhoer LS, Nakaya HI, Price AA, Grakoui A, Pulendran B. Chronic but not acute virus infection induces sustained expansion of myeloid suppressor cell numbers that inhibit viralspecific T cell immunity. Immunity. 2013; 38:309-321. [PubMed: 23438822]

32. Dunne PJ, Moran B, Cummins RC, Mills KH. CD11c+CD8alpha+ dendritic cells promote protective immunity to respiratory infection with Bordetella pertussis. J Immunol. 2009; 183:400 410. [PubMed: 19542451]

33. Ray JP, Marshall HD, Laidlaw BJ, Staron MM, Kaech SM, Craft J. Transcription factor STAT3 and type I interferons are corepressive insulators for differentiation of follicular helper and T helper 1 cells. Immunity. 2014; 40:367-377. [PubMed: 24631156]

34. Tussiwand R, Everts B, Grajales-Reyes GE, Kretzer NM, Iwata A, Bagaitkar J, Wu X, Wong R, Anderson DA, Murphy TL, Pearce EJ, et al. Klf4 expression in conventional dendritic cells is required for T helper 2 cell responses. Immunity. 2015; 42:916-928. [PubMed: 25992862]

35. Muller F, Aukrust P, Nordoy I, Froland SS. Possible role of interleukin-10 (IL-10) and CD40 ligand expression in the pathogenesis of hypergammaglobulinemia in human immunodeficiency virus infection: modulation of IL-10 and Ig production after intravenous Ig infusion. Blood. 1998; 92:3721-3729. [PubMed: 9808566]

36. Kacani L, Stoiber H, Dierich MP. Role of IL-15 in HIV-1-associated hypergammaglobulinaemia. Clin Exp Immunol. 1997; 108:14-18. [PubMed: 9097905]

37. Osmond DG. The turnover of B-cell populations. Immunol Today. 1993; 14:34-37. [PubMed: 8442861]

38. Richter K, Perriard G, Oxenius A. Reversal of chronic to resolved infection by IL-10 blockade is LCMV strain dependent. Eur J Immunol. 2013; 43:649-654. [PubMed: 23348876]

39. Macchia D, Almerigogna F, Parronchi P, Ravina A, Maggi E, Romagnani S. Membrane tumour necrosis factor-alpha is involved in the polyclonal B-cell activation induced by HIV-infected human T cells. Nature. 1993; 363:464-466. [PubMed: 7684824]

40. Flatz L, Bergthaler A, de la Torre JC, Pinschewer DD. Recovery of an arenavirus entirely from RNA polymerase I/II-driven cDNA. Proc Natl Acad Sci U S A. 2006; 103:4663-4668. [PubMed: 16537369]

41. Kalhoro NH, Veits J, Rautenschlein S, Zimmer G. A recombinant vesicular stomatitis virus replicon vaccine protects chickens from highly pathogenic avian influenza virus (H7N1). Vaccine. 2009; 27:1174-1183. [PubMed: 19135116]

42. Bergthaler A, Merkler D, Horvath E, Bestmann L, Pinschewer DD. Contributions of the LCMV glycoprotein and polymerase to strain-specific differences in murine liver pathogenicity. J Gen Virol. 2007; 88:592-603. [PubMed: 17251578]

43. Eschli B, Zellweger RM, Wepf A, Lang KS, Quirin K, Weber J, Zinkernagel RM, Hengartner H. Early antibodies specific for the neutralizing epitope on the receptor binding subunit of the lymphocytic choriomeningitis virus glycoprotein fail to neutralize the virus. J Virol. 2007; 81:11650-11657. [PubMed: 17699567]

44. Dobin A, Davis CA, Schlesinger F, Drenkow J, Zaleski C, Jha S, Batut P, Chaisson M, Gingeras TR. STAR: ultrafast universal RNA-seq aligner. Bioinformatics. 2013; 29:15-21. [PubMed: 23104886] 
45. Gaidatzis D, Lerch A, Hahne F, Stadler MB. QuasR: quantification and annotation of short reads in R. Bioinformatics. 2015; 31:1130-1132. [PubMed: 25417205]

46. R C Team. R: A language and environment for statistical computing. R Foundation for Statistical Computing; Vienna, Austria: 2015. http://www.r-project.org/

47. McCarthy DJ, Chen Y, Smyth GK. Differential expression analysis of multifactor RNA-Seq experiments with respect to biological variation. Nucleic Acids Res. 2012; 40:4288-4297. [PubMed: 22287627]

48. Law CW, Chen Y, Shi W, Smyth GK. voom: Precision weights unlock linear model analysis tools for RNA-seq read counts. Genome Biol. 2014; 15:R29. [PubMed: 24485249]

49. Gu Z. ComplexHeatmap: Making Complex Heatmaps R package version 1.10.2. 2016 https:// github.com/jokergoo/ComplexHeatmap.

50. Muller U, Steinhoff U, Reis LF, Hemmi S, Pavlovic J, Zinkernagel RM, Aguet M. Functional role of type I and type II interferons in antiviral defense. Science. 1994; 264:1918-1921. [PubMed: 8009221]

51. Laubach VE, Shesely EG, Smithies O, Sherman PA. Mice lacking inducible nitric oxide synthase are not resistant to lipopolysaccharide-induced death. Proc Natl Acad Sci U S A. 1995; 92:1068810692. [PubMed: 7479866]

52. Roths JB, Murphy ED, Eicher EM. A new mutation, gld, that produces lymphoproliferation and autoimmunity in C3H/HeJ mice. J Exp Med. 1984; 159:1-20. [PubMed: 6693832]

53. Boring L, Gosling J, Chensue SW, Kunkel SL, Farese RV Jr, Broxmeyer HE, Charo IF. Impaired monocyte migration and reduced type 1 (Th1) cytokine responses in C-C chemokine receptor 2 knockout mice. J Clin Invest. 1997; 100:2552-2561. [PubMed: 9366570]

54. Prinz M, Schmidt H, Mildner A, Knobeloch KP, Hanisch UK, Raasch J, Merkler D, Detje C, Gutcher I, Mages J, Lang R, et al. Distinct and nonredundant in vivo functions of IFNAR on myeloid cells limit autoimmunity in the central nervous system. Immunity. 2008; 28:675-686. [PubMed: 18424188]

55. Kreuzaler M, Rauch M, Salzer U, Birmelin J, Rizzi M, Grimbacher B, Plebani A, Lougaris V, Quinti I, Thon V, Litzman J, et al. Soluble BAFF levels inversely correlate with peripheral B cell numbers and the expression of BAFF receptors. J Immunol. 2012; 188:497-503. [PubMed: 22124120]

56. Horai R, Asano M, Sudo K, Kanuka H, Suzuki M, Nishihara M, Takahashi M, Iwakura Y. Production of mice deficient in genes for interleukin (IL)-1alpha, IL-1beta, IL-1alpha/beta, and IL-1 receptor antagonist shows that IL-1beta is crucial in turpentine-induced fever development and glucocorticoid secretion. J Exp Med. 1998; 187:1463-1475. [PubMed: 9565638]

57. Kuhn R, Rajewsky K, Muller W. Generation and analysis of interleukin-4 deficient mice. Science. 1991; 254:707-710. [PubMed: 1948049]

58. Kopf M, Baumann H, Freer G, Freudenberg M, Lamers M, Kishimoto T, Zinkernagel R, Bluethmann H, Kohler G. Impaired immune and acute-phase responses in interleukin-6-deficient mice. Nature. 1994; 368:339-342. [PubMed: 8127368]

59. Rickert RC, Roes J, Rajewsky K. B lymphocyte-specific, Cre-mediated mutagenesis in mice. Nucleic Acids Res. 1997; 25:1317-1318. [PubMed: 9092650]

60. Kuhn R, Lohler J, Rennick D, Rajewsky K, Muller W. Interleukin-10-deficient mice develop chronic enterocolitis. Cell. 1993; 75:263-274. [PubMed: 8402911]

61. Fung-Leung WP, Schilham MW, Rahemtulla A, Kundig TM, Vollenweider M, Potter J, van Ewijk W, Mak TW. CD8 is needed for development of cytotoxic T cells but not helper T cells. Cell. 1991; 65:443-449. [PubMed: 1673361]

62. Magram J, Connaughton SE, Warrier RR, Carvajal DM, Wu CY, Ferrante J, Stewart C, Sarmiento U, Faherty DA, Gately MK. IL-12-deficient mice are defective in IFN gamma production and type 1 cytokine responses. Immunity. 1996; 4:471-481. [PubMed: 8630732]

63. Lee PP, Fitzpatrick DR, Beard C, Jessup HK, Lehar S, Makar KW, Perez-Melgosa M, Sweetser MT, Schlissel MS, Nguyen S, Cherry SR, et al. A critical role for Dnmt1 and DNA methylation in T cell development, function, and survival. Immunity. 2001; 15:763-774. [PubMed: 11728338]

64. Caton ML, Smith-Raska MR, Reizis B. Notch-RBP-J signaling controls the homeostasis of CD8dendritic cells in the spleen. J Exp Med. 2007; 204:1653-1664. [PubMed: 17591855] 
65. Clausen BE, Burkhardt C, Reith W, Renkawitz R, Forster I. Conditional gene targeting in macrophages and granulocytes using LysMcre mice. Transgenic Res. 1999; 8:265-277. [PubMed: 10621974]

66. Schaefer BC, Schaefer ML, Kappler JW, Marrack P, Kedl RM. Observation of antigen-dependent CD8+ T-cell/ dendritic cell interactions in vivo. Cell Immunol. 2001; 214:110-122. [PubMed: 12088410]

67. Grimaldi JC, Yu NX, Grunig G, Seymour BW, Cottrez F, Robinson DS, Hosken N, Ferlin WG, Wu $\mathrm{X}$, Soto H, O'Garra A, et al. Depletion of eosinophils in mice through the use of antibodies specific for C-C chemokine receptor 3 (CCR3). J Leukoc Biol. 1999; 65:846-853. [PubMed: 10380909]

68. Rose S, Misharin A, Perlman H. A novel Ly6C/Ly6G-based strategy to analyze the mouse splenic myeloid compartment. Cytometry A. 2012; 81:343-350. [PubMed: 22213571] 


\section{One-sentence summary}

Interferon-driven inflammation in chronic viral infection orchestrates unsustainable B cell response. 


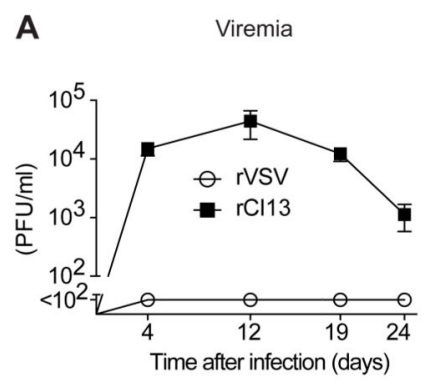

E

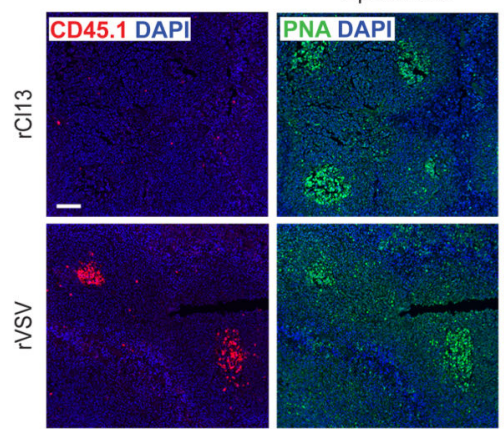

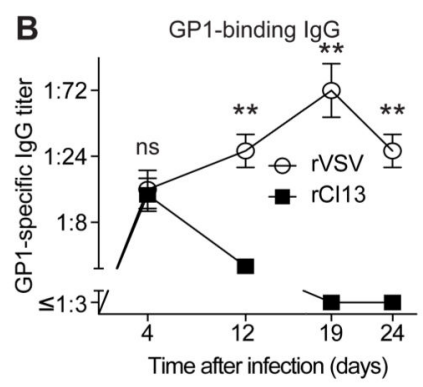

$\mathbf{F}$

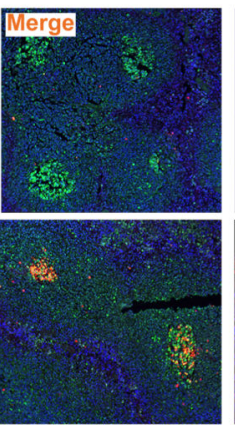

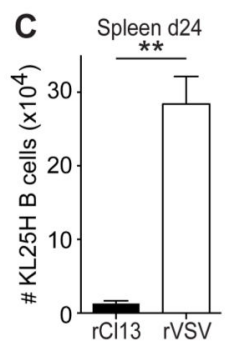
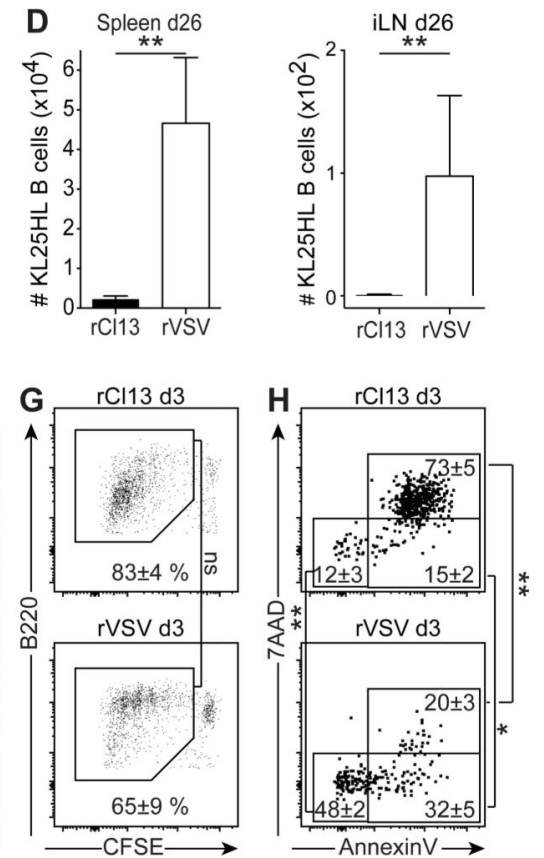

Fig. 1. Depletion of virus-specific B cells at the onset of rCl13 but not rVSV infection.

A: We infected wt mice with rCl13 or rVSV and measured viremia on the indicated days. B-H: We adoptively transferred KL25H (B,C) or KL25HL cells (D-H) into naïve syngeneic recipients, followed by rCl13 or rVSV challenge. On the indicated days, KL25H-derived GP1-binding IgG were determined (B). Progeny B cells were enumerated by flow cytometry in spleen and iLN (C,D). KL25HL B cells (CD45.1 $\left.{ }^{+}\right)$in germinal centers (E, bar $\left.100 \mu \mathrm{m}\right)$ and their abortive expansion following rCl13 infection (F, magnification bar $50 \mu \mathrm{m}$, inset 20 $\mu \mathrm{m})$ by histology. Proliferation (CFSE dilution) of d3 rCl13- and rVSV-challenged KL25HL B cells, gated on CD45.1 $1^{+} \mathrm{B} 220^{+}$lymphocytes $(\mathrm{G}$; background proliferation of CD $45.1^{+} \mathrm{B} 220^{+}$lymphocytes in uninfected controls was $1.2 \pm 0.2 \%$ (mean \pm SEM), not displayed). Apoptotic (AnnexinV ${ }^{+} / 7 \mathrm{AAD}^{+}$) KL25HL B cells on d3 of rCl13 or rVSV challenge, gated on CD45.1 $1^{+} \mathrm{B} 220^{+} \mathrm{CFSE}^{\text {lo }}$ lymphocytes $(\mathrm{H})$. Gating is shown in Fig. S1C.

Numbers in FACS plots indicate percentages (mean \pm SEM). Symbols and bars represent mean \pm SEM. Number of biological replicates $(n)=3-4(\mathrm{~A}-\mathrm{C}), n=4(\mathrm{D}-\mathrm{F}), n=3(\mathrm{G}, \mathrm{H})$.

Number of independent experiments $(N)=2$. Unpaired two-tailed Student's $t$ tests $(C-D, G)$, two-way analysis of variance (ANOVA) with Bonferroni's post-test for multiple comparisons $(\mathrm{B}, \mathrm{H})$. ns: not significant; *: $p<0.05 ; * *: p<0.01$. 

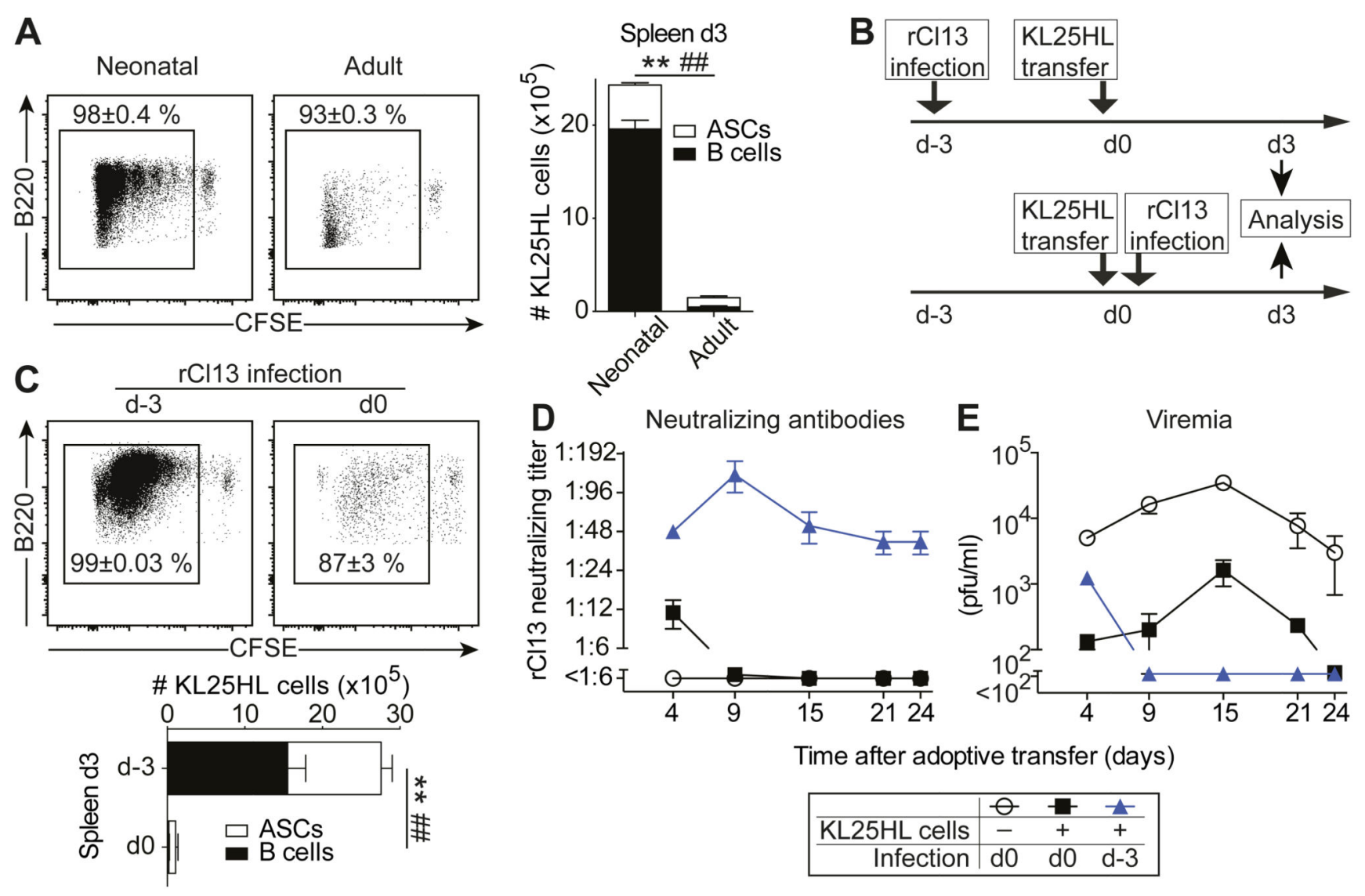

Fig. 2. B cell "decimation" correlates with the time point of cell transfer rather than with antigen load

A: We adoptively transferred KL25HL cells into neonatally infected rCl13 carriers or adult rCl13-infected mice on $\mathrm{d} 0$ and measured $\mathrm{B}$ cell proliferation and progeny (B cells and ASCs) on day 3 in spleen.

B-E: Upon KL25HL transfer and rCl13 infection, timed as outlined (B), we measured KL25HL B cell proliferation and expansion (C), nAb responses (D) and viremia (E). Numbers in FACS plots indicate percentages (mean \pm SEM). FACS plots are gated on CD 45.1 ${ }^{+}$B220 ${ }^{+}$lymphocytes. B cell and ASC gating is shown in Fig. S2A. Symbols and bars represent mean \pm SEM. $n=3, N=2$ (A), $N=3$ (C-E). Two-way ANOVA with Bonferroni's post-test for multiple comparisons (A,C). **,\#\#: $p<0.01$; ** compares B cells; \#\# compares ASCs. 

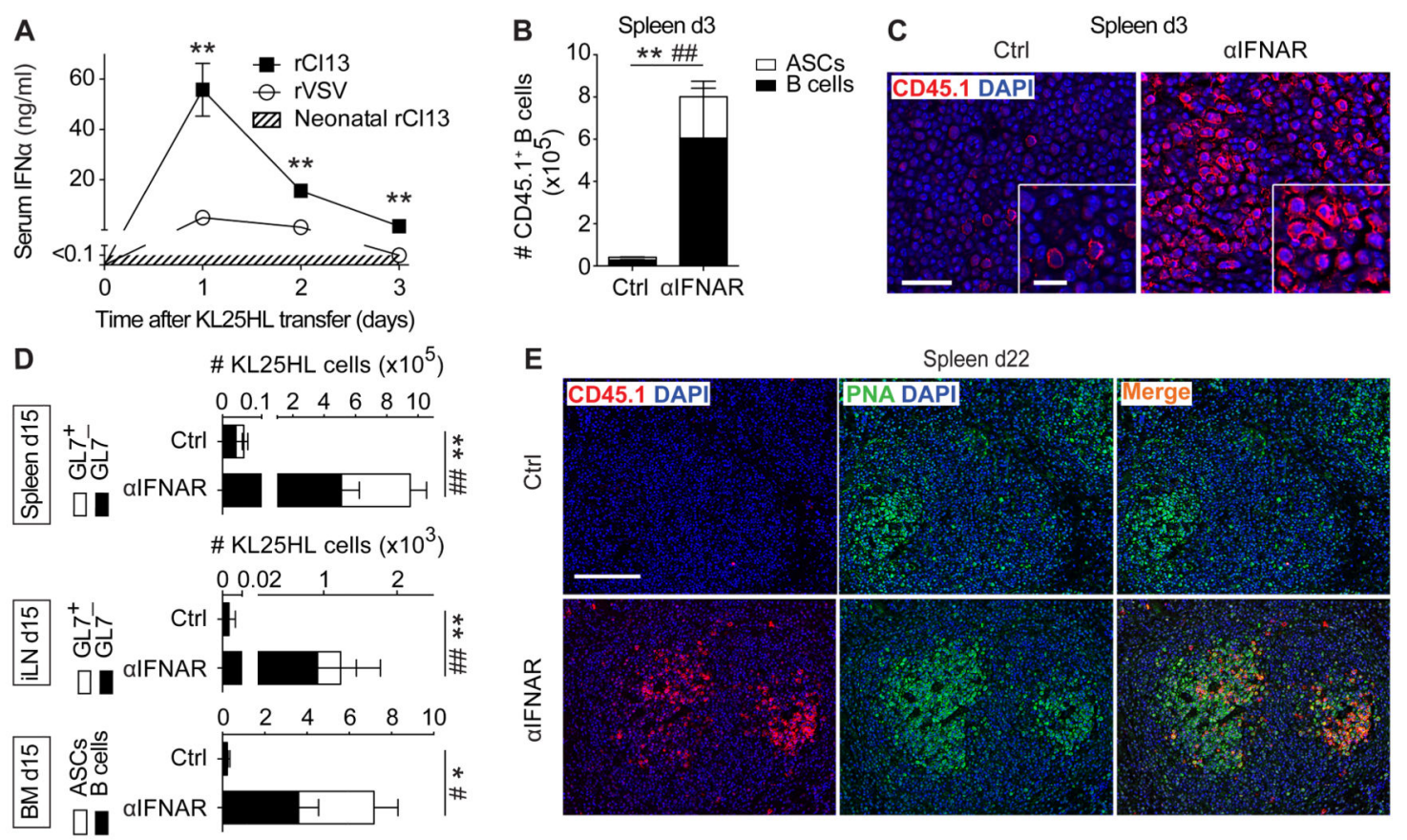

F \# mem KL25H B cell progeny $\left(\times 10^{4}\right)$

G
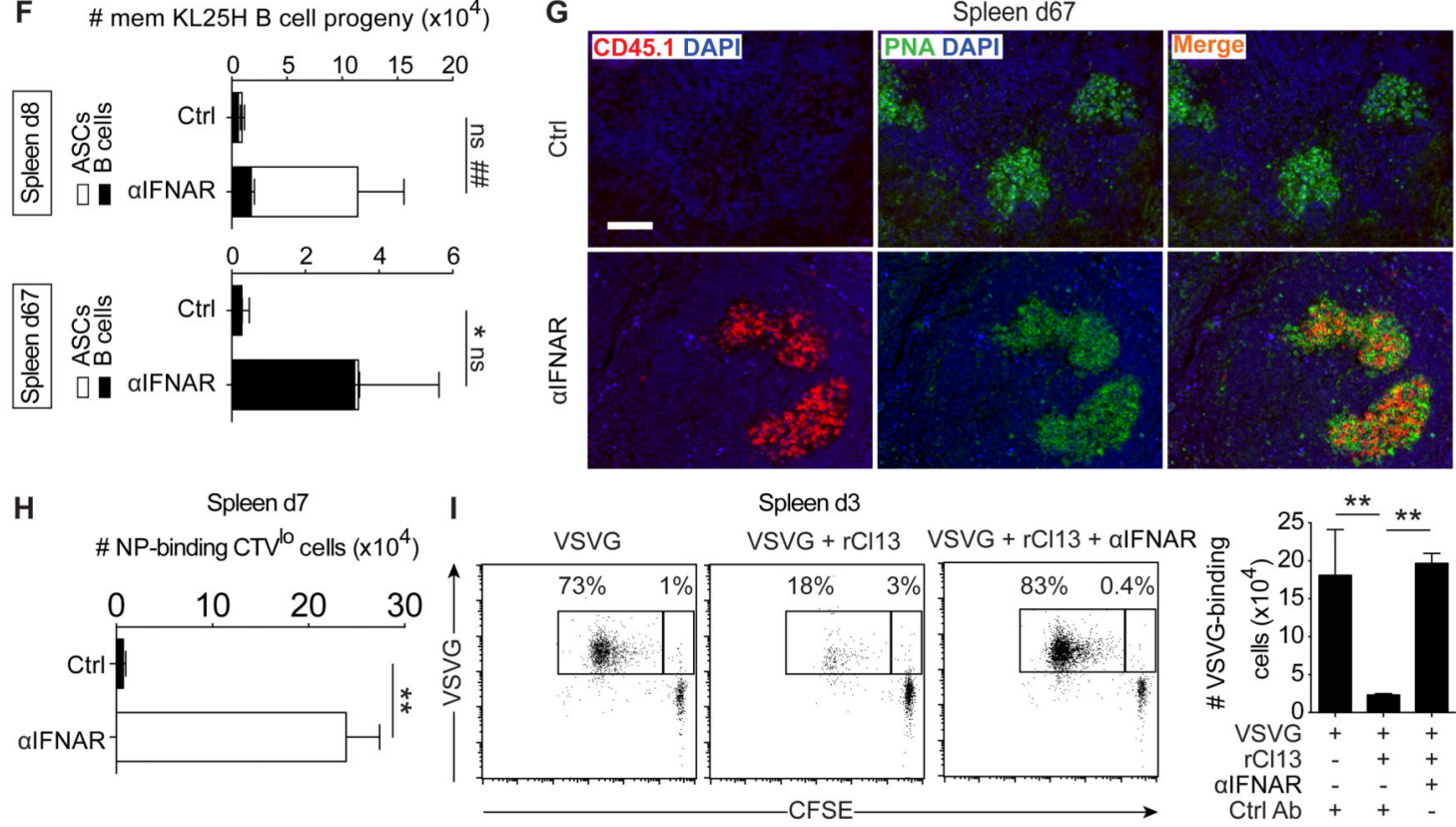

Fig. 3. IFNAR blockade restores B cell expansion and GC B cell differentiation in rCl13 infection.

A: Serum IFN-a in KL25HL cell recipients, infected with rCl13 at birth or on d0, or infected with rVSV on d0.

B-H: We transferred naïve KL25HL cells (B-E), antigen-experienced KL25H B cells (F-G) or antigen-experienced polyclonal $\mathrm{GFP}^{+} \mathrm{B}$ cells $(\mathrm{H})$ to aIFNAR- or control-treated wt recipients, followed by rCl13 infection (see Figs. S3B-D and and S3F for experimental design and characterization of transferred cells). B cell progeny in the indicated organs were detected by FACS (B,D,F,H) and histology (C,E,G). Note progeny of naïve KL25HL cells 
(E) and of antigen-experienced KL25H cells (G) in GCs of IFNAR-blocked recipients. Magnification bars: $50 \mu \mathrm{m}$, inset $20 \mu \mathrm{m}(\mathrm{C}) ; 200 \mu \mathrm{m}(\mathrm{E}) ; 100 \mu \mathrm{m}(\mathrm{G})$. Numbers in (H) represent LCMV-NP-binding (see Fig. S3G), proliferated (CellTraceViolet/CTVlo) polyclonal donor $\left(\mathrm{GFP}^{+}\right) \mathrm{B}$ cell progeny $\left(\mathrm{CTV}^{\mathrm{lo}} \mathrm{GFP}^{+} \mathrm{LCMV}^{-\mathrm{NP}^{+}}\right.$) lymphocytes. (gating shown in S2A for B, F and S3A for D)

I: We transferred naïve VI10 cells to aIFNAR- or control-treated recipients, followed by VSVG immunization, alone or in combination with rCl13 infection. Proliferated (CFSE ${ }^{\text {lo }}$ ) VSVG-binding VI10 B cells were enumerated by FACS. Plots are gated on CD45.2 $2^{+} \mathrm{B} 220^{+}$ lymphocytes, numbers indicate percentages. Symbols and bars represent mean \pm SEM. $n=3-4$ (A,F), $n=3$ (D), $n=4$ (B,C,E,G-I). $N=2-3$ (F), $N=2$ (A,C-E,G), N=3 (B,H,I). Two-way ANOVA with Bonferroni's post-test for multiple comparisons (A,B,D,F), unpaired twotailed Student's $t$ test $(\mathrm{H})$, one-way ANOVA with Bonferroni's post-test for multiple comparisons (I). ns: not significant; *,\#: $p<0.05 ; * *$,\#\#: $p<0.01 . * * *$ compare total or GL7 ${ }^{+}$ B cells; \#,\#\# compare ASCs or GL7 B cells, respectively. 


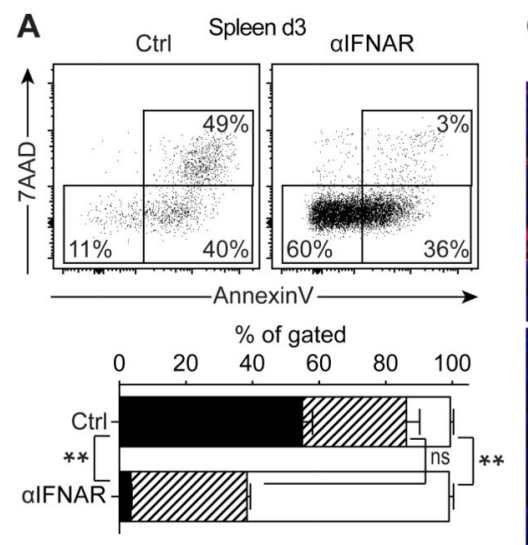

7AAD $^{+}$Annex $^{+}$שב 7AAD-Annex ${ }^{+}$ $\square$ 7AAD- Annex-
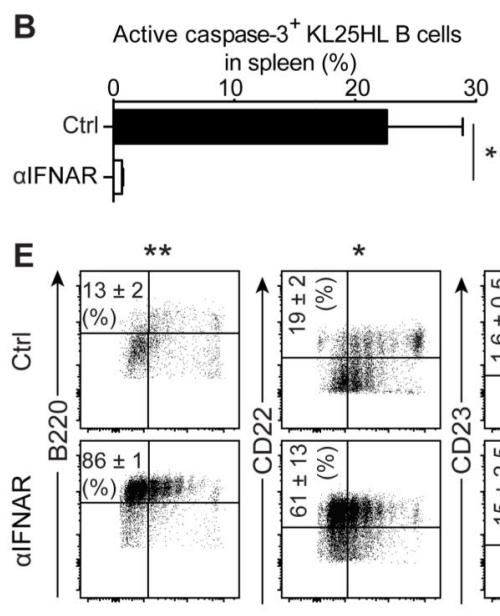

C
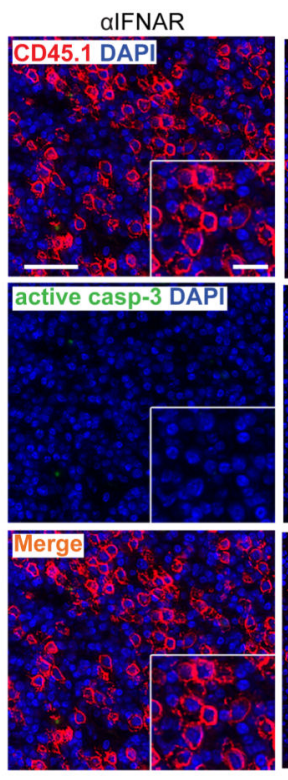$$
\text { . }
$$

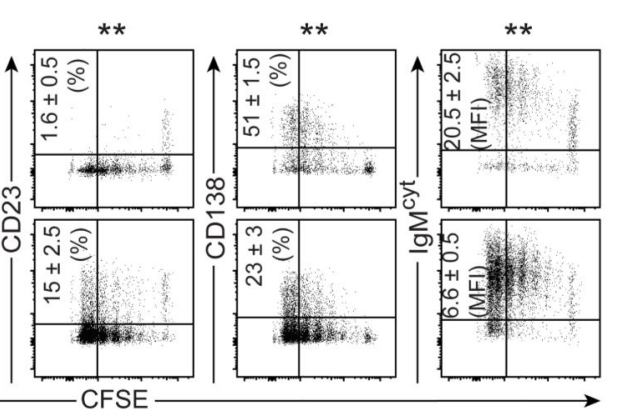

D
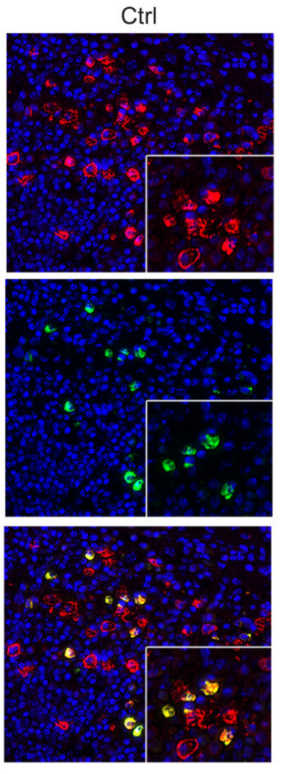

$\mathbf{F}$

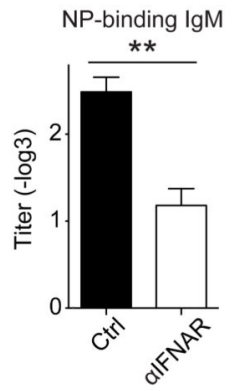

ASC signature genes
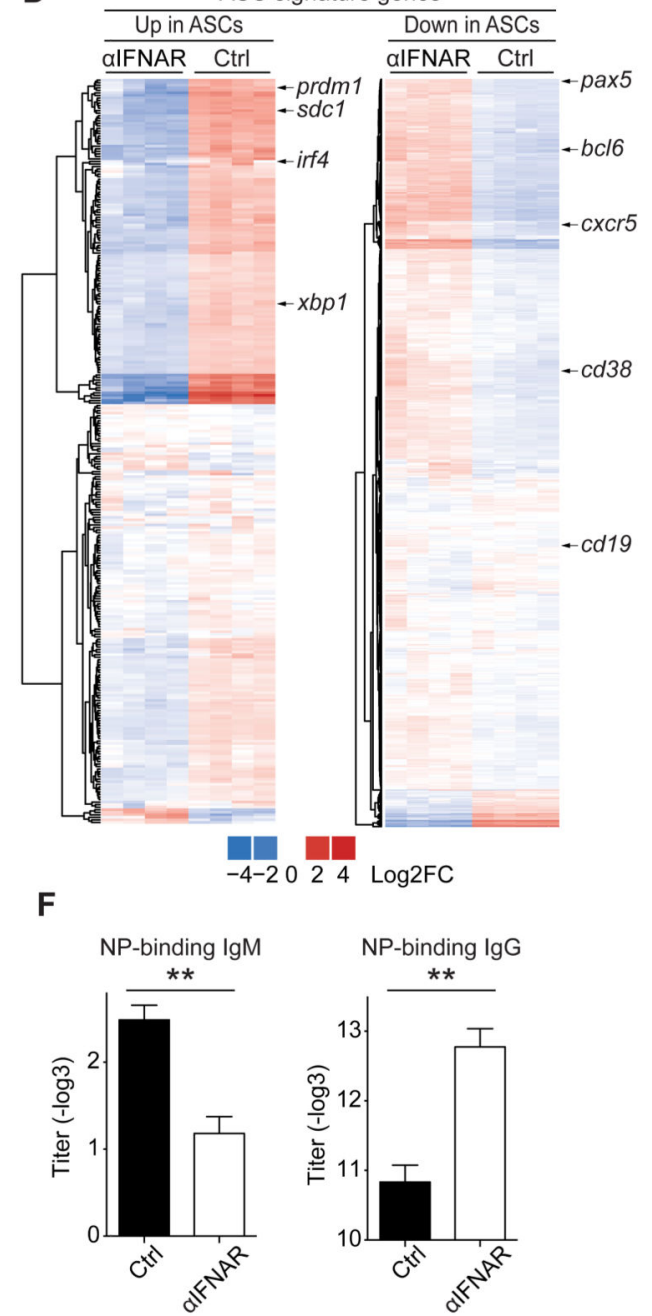

Fig. 4. IFN-I-induced short-lived plasmablast differentiation in rCl13 infection.

A-D: We transferred naïve KL25HL cells to aIFNAR- or control-treated recipients, followed by $\mathrm{rCl} 13$ infection and analysis in spleen on day 3. Apoptotic KL25HL B cell were identified in FACS based on AnnexinV/7AAD-binding (A) and by histology based on expression of active caspase-3 (B,C, magnification bar $50 \mu \mathrm{m}$, inset $20 \mu \mathrm{m}$ ). Proliferated KL25HL B cell progeny $\left(\mathrm{CD} 45.1^{+} \mathrm{B} 220^{+} \mathrm{CFSE}^{\mathrm{lo}}\right)$ were FACS-sorted and total RNA was processed for RNAseq (D). Heat maps show expression profiles of ASC signature genes known to be upregulated (left) or downregulated (right) upon ASC differentiation, respectively (27). Each column represents one biological replicate. Self-contained gene set testing is shown in Fig. S5A. Plasmablast differentiation of proliferated (CFSE ${ }^{\text {lo }}$ ) KL25HL B cell progeny was determined by flow cytometry (E). Numbers in FACS plots indicate the percentage of cells falling into the respective gate (A, representative FACS plots, gated as shown in Fig. S1C), the percentage of CFSE ${ }^{\text {lo }}$ cells expressing the respective marker (E) or the MFI of cytoplasmic IgM within IgM ${ }^{\text {cyt }}{ }^{+} \mathrm{CFSE}^{\text {lo }}$ cells (E, mean \pm SEM).

F: We infected aIFNAR- or control-treated wt mice with rCl13 and measured NP-binding antibody responses. Bars show mean \pm SEM. $n=3$ (A), $n=3-4$ (B,C,E), $n=4$ (D) and $n=4-5$ (F). 
$N=2$ (A-C,E), $N=1$ (D,F). Two-way ANOVA with Bonferroni's post-test for multiple comparisons (A), unpaired two-tailed Student's $t$ test (B,E,F). ns: not significant; *: $p<0.05$; $* *: p<0.01$. 
A

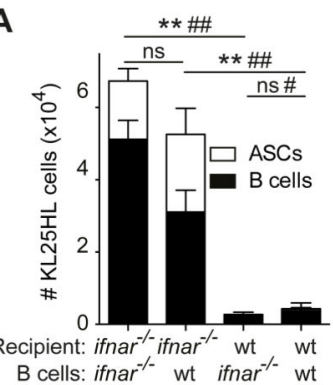

B

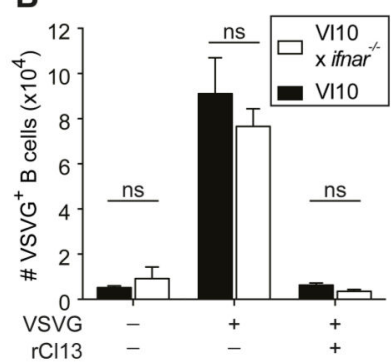

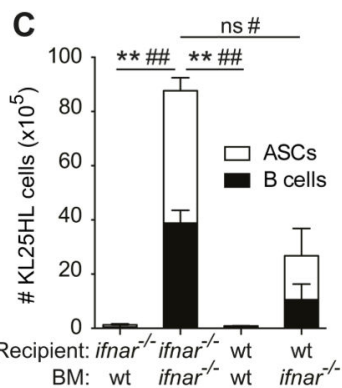

G
$\mathbf{F}$

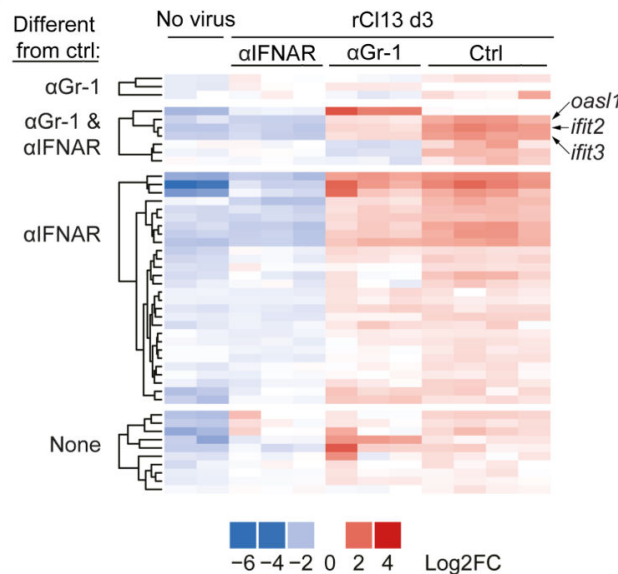

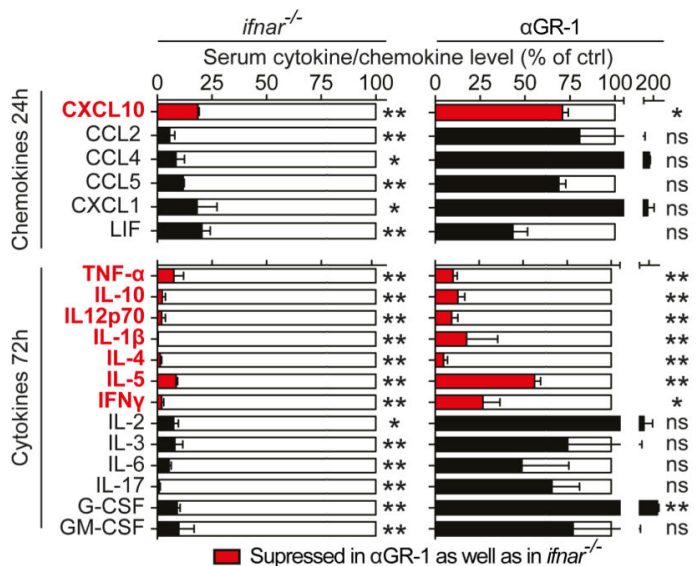

D

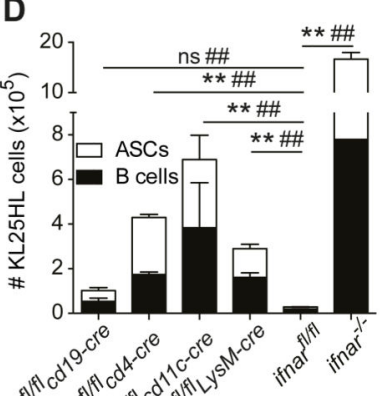

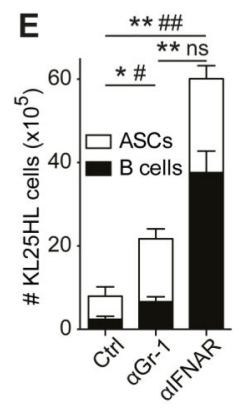

H

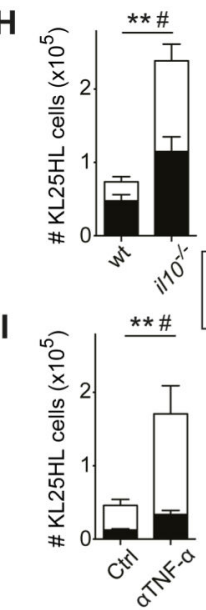

Fig. 5. Decimation results from IFN-I effects on hematopoietic cells other than B cells, and is due to inflammation including IL-10 and TNF- $a$.

A: We transferred KL25HL cells, either wt or ifnar ${ }^{-/}$, into wt or ifnar ${ }^{-/-}$recipients and enumerated splenic KL25HL B cell progeny on d3 after rCl13 infection.

B: We transferred VI10 cells, either wt or ifnar ${ }^{-/}$, into wt recipients, followed by VSVG immunization and rCl13 infection as indicated, and enumerated splenic VSVG-binding VI10 B cells on $\mathrm{d} 3$.

C-D: We transferred KL25HL cells into reciprocal wt and ifnar ${ }^{-/-}$BM chimeras (C) or into recipients with cell type-specific, conditional or complete IFNAR deficiency (D) and enumerated splenic KL25HL B cell progeny on d3 after rCl13 infection.

E: We transferred KL25HL cells into wt recipients, treated with a Gr-1, aIFNAR or control antibody, and enumerated splenic KL25HL B cell progeny on $\mathrm{d} 3$ after rCl13 infection. F: Low density inflammatory gene expression profiling in spleen of naïve or $\mathrm{d} 3 \mathrm{rCl13}$ infected KL25HL recipients. Heat map showing the 48 genes significantly up-regulated upon rCl13 infection. Each column represents one biological replicate.

G: Serum chemokines and cytokines were profiled at $24 \mathrm{~h}$ and $72 \mathrm{~h}$ after $\mathrm{rCl} 13$, respectively. ifnar ${ }^{r-}$ and a Gr-1-treated wt mice are expressed as percentage of control-treated wt mice.

Only those 19/31 profiled chemokines and cytokines are displayed, which were $\geq 4$-fold lower in ifnar ${ }^{/-}$than wt controls (Tbl. SII). Red bars indicate chemokines/cytokines that were suppressed in ifnar ${ }^{-/}$and aGr-1-treated mice. Log-converted chemokine and cytokine concentrations were used for statistical analysis.

H-I: We transferred KL25HL cells into il-10/- or wt recipients (H) or into wt recipients, treated with a TNF-a or control antibody (I), and enumerated splenic KL25HL B cell 
progeny on $\mathrm{d} 3$ after rCl13 infection. B cells and ASCs were gated as shown in Fig. S2A. Bars show mean \pm SEM. $n=3-4$ (A), $n=3$ (B, unimmunized:2, G), $n=4$ (C,E,H,I) $n=3-6$ (D), $n=2-4(\mathrm{~F}) . \quad N=2$ (B,C,I), N=3 (A,D,E,H), N=1 (F,G). ns: not significant; *,\#: $p<0.05$; **,\#\#: $p<0.01$. Two-way ANOVA with Bonferroni's (A,B,E,H,I,G) or Dunnett's (C,D) post-test for multiple comparisons. *** compare B cells; \#,\#\# compare ASCs. 